\title{
Pengaruh Pupuk Organik Padat dan Varietas pada Produktivitas Tebu (Saccharum officinarum L.)
}

\section{(Effects of Solid Organic Fertilizer Application and Variety on Productivity of Sugarcane [Saccharum officinarum L.])}

\author{
Eka Risdianti Asmaning Ayu ${ }^{1)}$, Wiwik Indrawati ${ }^{2 *}$, Albertus Sudirman ${ }^{2)}$ \\ 1) Program Studi Produksi dan Manajemen Industri Perkebunan Politeknik Negeri Lampung dan \\ 2) Jurusan Budidaya Tanaman Perkebunan Politeknik Negeri Lampung, Jl. Soekarno-Hatta No. 10 \\ Rajabasa, Bandar Lampung, 35144, Telp.: (0721) 703995, Fax.: (0721) 787309 \\ E-mail:wiwik@polinela.ac.id
}

\begin{abstract}
Sugarcane is one of the main sugar-producing commodities in Indonesia. The one of the efforts to increase the production and yield of sugarcane can be done by fertilization using organic fertilizer and the use of improved varieties. The aim of this research are to get optimal rate of solid organic fertilizer, the best sugarcane variety, and interaction between solid organic fertilizer rate and variety on productivity of sugarcane. The study was conducted in December 2015 until December 2016 at Teaching Farm and Chemical Analysis Laboratory, State P olytechnic of Lampung. The research used Factorial Random Block Design method, with two factors. The first factor is the rate of solid organic fertilizer (Control, $1.000 \mathrm{~kg} . \mathrm{ha}^{-1}, 1.500 \mathrm{~kg} . \mathrm{ha}^{-1}$, and $2.000 \mathrm{~kg} . \mathrm{ha}^{-1}$ ), whereas the second factor is sugarcane varieties (GMP 3, GMP 19, and SS 57). The data of the research were analyzed by analysis of variance and if the result was significantly different then continued by using LSD test of 5\% level. The results showed that there was interaction between the use of solid organic fertilizer $1000 \mathrm{~kg} . \mathrm{ha}^{-1}$ and GMP 3 varieties on variable length of sugarcane stem. The productivity of sugarcane crops can be improved by the application of $1000 \mathrm{~kg} . \mathrm{ha}^{-1}$ solid organic fertilizer which influences the variables of sugarcane quantity per lube and the number of sugarcane segments. The best variety that can be used to increase the productivity of sugarcane is GMP 3.
\end{abstract}

Keywords: solid organic fertilizer, sugarcane productivity, sugarcane varieties

Diterima: 21 Juli 2017 / Disetujui: 30 September 2017 / Diterbitkan: 20 Oktober 2017

\section{PENDAHULUAN}

Tanaman tebu (Saccharum officinarum L.) merupakan salah satu tanaman sebagai bahan baku pembuatan gula. Produktivitas tebu nasional pada tahun 2015 hanya mencapai $4.062 \mathrm{~kg}^{-h a^{-1}}$ (Direktorat Jenderal Perkebunan, 2014). Hal ini disebabkan karena menurunnya kadar bahan organik, yang berdampak pada rendahnya keadaan fisik, biologi, dan kimia tanah sehingga dapat menurunkan kualitas tanah. Keadaan tersebut akan berpengaruh terhadap kemampuan tanaman untuk sintesis biomassa sehingga terjadi penurunan produksi tebu (Crasswell \& Lefroy, 2001).

Penggunaan pupuk anorganik berpengaruh pada menurunnya kesuburan tanah dan terganggunya keseimbangan ekosistem tanah. Oleh karena itu, perlu adanya alternatif pengganti 
pupuk anorganik yang dapat meningkatkan hasil dan rendemen tebu. Pupuk organik diharapkan dapat menjadi alternatif pengganti pupuk anorganik.

Pupuk organik dapat menambah unsur hara, menambah mikrobia dalam tanah, memperbaiki struktur tanah, mengikat unsur nitrogen, melarutkan fosfat, mengurai kalium, merangsang pertumbuhan tanaman, menetralisir zat kimia yang bersifat racun ( $\mathrm{Al} \mathrm{dan} \mathrm{Fe}$ ) dalam tanah, mengurangi kerontokan bunga dan buah, mereduksi penggunaan pupuk anorganik, meningkatkan kualitas dan kuantitas produksi tanaman, dan membuat tanaman menjadi lebih tahan terhadap serangan hama (Khairullah et al., 2010). Penggunaan varietas unggul diharapkan mampu meningkatkan hasil dari rendemen tebu. Varietas unggul tersebut yaitu GMP 3, GMP 19, dan SS 57. Penggunaan pupuk organik dan juga tiga varietas unggul diharapkan dapat meningkatkan rendemen dan produktivitas tebu.

Berdasarkan hal diatas tersebut, maka dilakukan penelitian dengan tujuan untuk mendapatkan dosis pupuk yang optimal terhadap produktivitas tebu, mendapatkan varietas terbaik yang dapat meningkatkan produktivitas tebu, dan mendapatkan interaksi antara dosis pupuk dan varietas terhadap produktivitas tebu.

\section{METODE PENELITIAN}

Penelitian dilaksanakan pada bulan Desember 2015 sampai dengan Desember 2016 di Kebun Penelitian dan Laboratorium Analisis Kimia Politeknik Negeri Lampung. Bahan dan alat yang digunakan adalah bibit bagal tebu (varietas GMP 3, GMP 19, dan SS 57) dan pupuk organik padat dengan merek dagang Ghaly Organik ${ }^{\circledR}$. Alat yang digunakan adalah parang, meteran, becker glass, timbangan, tabung reaksi, High Performance Liquid Chromatography (HPLC), amplop coklat, dan alat tulis.

Percobaan ini menggunakan Rancangan Acak Kelompok (RAK) pola faktorial dengan 2 faktor perlakuan. Faktor pertama yaitu dosis pupuk organik padat 4 taraf $\mathrm{O}_{0}$ (kontrol), $\mathrm{O}_{1}(1.000$ kg.ha $\left.{ }^{-1}\right), \mathrm{O}_{2}\left(1.500 \mathrm{~kg} \cdot \mathrm{ha}^{-1}\right), \mathrm{O}_{3}\left(2.000 \mathrm{~kg} \mathrm{ha}^{-1}\right)$ dan faktor kedua varietas tebu 3 taraf, yaitu $\mathrm{V}_{1}$ (GMP 3), $\mathrm{V}_{2}$ (GMP 19), dan $\mathrm{V}_{3}$ (SS 57), diperoleh 12 kombinasi perlakuan yang ulang sebanyak 3 kali sehingga terdapat 36 satuan percobaan.

Ketiga varietas yang digunakan dalam percobaan ditanam pada Desember 2015 dengan metode line spacing dengan jarak antarstek bagal tebu $5 \mathrm{~cm}$. Pupuk organik padat diberikan pada saat tanam dengan cara dibenamkan ke dalam kairan. Dosis pupuk organik padat diberikan sesuai dengan taraf perlakuan. Dosis pupuk organik padat 1.000 kg.ha ${ }^{-1}$ setara dengan 450 g.kairan-1, 1.500 kg.ha ${ }^{-1}$ setara dengan 670 g.kairan ${ }^{-1}$, dan 2.000 kg.ha ${ }^{-1}$ setara dengan 900 g.kairan ${ }^{-1}$.

Variabel yang diamati adalah tinggi batang, jumlah ruas tebu per batang, jumlah batang tebu per kairan, bobot tebu perkairan, dan kadar sukrosa. Data yang diperoleh dianalisis dengan 
menggunakan tabel sidik ragam. Apabila pada uji $\mathrm{F}$ terdapat perbedaan nyata, maka akan dilanjutkan dengan uji Beda Nyata Terkecil (BNT) pada taraf 5\%.

\section{HASIL DAN PEMBAHASAN}

\section{Tinggi Batang}

Berdasarkan hasil analisis sidik ragam menunjukkan bahwa variabel panjang batang pengamatan umur 6 sampai dengan 11 bulan setelah tanam (BST) tidak terjadi interaksi antara dosis pupuk organik padat dan varietas, tetapi berpengaruh nyata pada perlakuan varietas. Sedangkan pada umur 12 BST terjadi interaksi antara dosis pupuk organik padat dan varietas. Rerata pengaruh dosis pupuk organik padat dan varietas pada panjang batang tebu umur 6 BST sampai dengan 11 BST disajikan pada Tabel 1.

Tabel 1. Rerata pengaruh dosis pupuk organik padat dan varietas pada panjang batang tebu umur 6 BST sampai dengan $11 \mathrm{BST}$

\begin{tabular}{lllllll}
\hline \multirow{2}{*}{ Varietas } & \multicolumn{5}{c}{ Rerata panjang batang tebu $(\mathrm{cm})$} \\
\cline { 2 - 7 } & 6 BST & 7 BST & 8 BST & 9 BST & 10 BST & 11 BST \\
\hline GMP 3 & $223,58 \mathrm{~b}$ & $261,63 \mathrm{~b}$ & $287,25 \mathrm{~b}$ & $319,75 \mathrm{~b}$ & $347,00 \mathrm{~b}$ & $365,72 \mathrm{~b}$ \\
GMP 19 & $211,11 \mathrm{a}$ & $244,38 \mathrm{a}$ & $276,58 \mathrm{a}$ & $308,16 \mathrm{a}$ & $329,61 \mathrm{a}$ & $350,16 \mathrm{a}$ \\
SS 57 & $202,94 \mathrm{a}$ & $238,55 \mathrm{a}$ & $262,36 \mathrm{a}$ & $290,38 \mathrm{a}$ & $316,22 \mathrm{a}$ & $341,30 \mathrm{a}$ \\
\hline
\end{tabular}

Keterangan: Rerata pada kolom yang sama diikuti oleh huruf yang sama tidak berbeda nyata pada uji BNT taraf 5\%

Tabel 1 menunjukkan bahwa pemberian pupuk organik tidak memberikan pengaruh pada pemanjangan batang tebu. Hal ini sesuai dengan pernyataan Prayogo et al., (2016) bahwa untuk menghasilkan pertumbuhan yang optimal tanaman tebu membutuhkan masukan pupuk yang cukup tinggi sehingga kandungan unsur hara dapat terpenuhi dan produksinya menjadi optimal. Unsur hara yang terdapat dalam pupuk organik hanya sebagian kecil saja yang dapat dimanfaatkan langsung oleh tanaman sedangkan sebagiannya lagi akan terurai dalam jangka waktu yang cukup lama (Novizan, 2005; Sukmawan, 2016).

Varietas berpengaruh nyata pada panjang tebu, hal ini diduga karena varietas GMP 3 memiliki tinggi tanaman yang lebih baik serta sifat genetik yang lebih unggul dibandingkan GMP 19 dan SS 57. Perbedaan susunan genetik pada suatu tanaman menyebabkan tanaman tersebut memiliki keragaman penampilan dan fungsi yang di perlihatkan oleh keragaman pertumbuhan (Putra et al., 2016). 
Tabel 2 menunjukkan bahwa terjadi interaksi antara dosis pupuk organik padat dan varietas terhadap panjang batang tebu pada umur 12 BST. Panjang batang tertinggi ditunjukkan oleh varietas GMP 3 sedangkan terendah varietas SS 57. Rerata dosis pupuk tertinggi diperlihatkan pada perlakuan 1.000 kg.ha ${ }^{-1}$ dan terendah pada dosis pupuk kontrol, namun berdasarkan uji statistik menunjukkan tidak berbeda nyata. Interaksi terjadi pada kombinasi penggunaan dosis pupuk 1.000 $\mathrm{kg} \mathrm{ha}^{-1}$ dan penggunaan varietas GMP 3. Hal ini diduga varietas GMP 3 memiliki respons pemupukan yang lebih baik dibandingkan varietas lainnya, dengan dosis optimum yang diberikan yaitu $1.000 \mathrm{~kg} \mathrm{ha}^{-1}$.

Tabel 2. Rerata pengaruh dosis pupuk organik padat dan varietas terhadap panjang batang tebu umur $12 \mathrm{BST}$

\begin{tabular}{lcccc}
\hline \multirow{2}{*}{ Dosis pupuk organik padat } & \multicolumn{3}{c}{ Varietas } & \multirow{2}{*}{ Rata-rata } \\
\cline { 2 - 4 } & GMP3 & GMP 19 & SS 57 & \\
\hline Kontrol kg.ha $^{-1}$ & $387,00 \mathrm{~d}$ & $372,00 \mathrm{c}$ & $367,22 \mathrm{~b}$ & $375,40 \mathrm{a}$ \\
$1.000 \mathrm{~kg} \cdot \mathrm{ha}^{-1}$ & $403,33 \mathrm{e}$ & $343,88 \mathrm{~b}$ & $318,66 \mathrm{a}$ & $355,29 \mathrm{a}$ \\
$1.500 \mathrm{~kg} \cdot \mathrm{ha}^{-1}$ & $348,56 \mathrm{~b}$ & $362,22 \mathrm{~b}$ & $372,00 \mathrm{c}$ & $360,92 \mathrm{a}$ \\
$2.000 \mathrm{~kg} \cdot \mathrm{ha}^{-1}$ & $368,00 \mathrm{~b}$ & $348,22 \mathrm{~b}$ & $337,66 \mathrm{a}$ & $351,29 \mathrm{a}$ \\
\hline Rata-rata & $376,72 \mathrm{~b}$ & $356,58 \mathrm{a}$ & $348,88 \mathrm{a}$ & \\
\hline
\end{tabular}

$\overline{\text { Keterangan: Rerata pada kolom yang sama diikuti oleh huruf yang sama tidak berbeda nyata pada }}$ uji BNT taraf 5\%

\section{Bobot Tebu per Kairan}

Berdasarkan hasil analisis sidik ragam, perlakuan pemberian dosis pupuk organik padat tidak berpengaruh terhadap penambahan bobot tebu, sedangkan penggunaan varietas berpengaruh nyata terhadap penambahan bobot tebu. Tidak terjadi interaksi pada penambahan bobot tebu tersebut (Tabel 3).

Perlakuan pemberian dosis pupuk organik padat tidak berpengaruh nyata pada penambahan bobot tebu per kairan seperti yang tertera pada Tabel 3. Hal ini diduga karena rendahnya kandungan unsur hara yang terdapat pada pupuk organik padat tersebut. Hasil uji laboratorium Politeknik Negeri Lampung menunjukkan hasil kandungan unsur hara berupa N, P, K berturutturut adalah 0,24\%, 0,64\%, dan 2,22\%. Menurut Rahardjo \& Ekwas (2010) jumlah, jenis, dan keseimbangan unsur hara makro (NPK) berpengaruh pada pertumbuhan tanaman yang berdampak pada produktivitas. 
Tabel 3. Rerata pengaruh dosis pupuk organik padat dan varietas padabobot tebu per kairan

\begin{tabular}{ll}
\hline Perlakuan & $\begin{array}{c}\text { Rerata bobot tebu per kairan } \\
\left(\mathrm{kg} \cdot \mathrm{kairan}^{-1}\right)\end{array}$ \\
\hline Dosis pupuk organik padat & $63,82 \mathrm{a}$ \\
\hline Kontrol & $63,61 \mathrm{a}$ \\
$1.000 \mathrm{~kg} \cdot \mathrm{ha}^{-1}$ & $63,02 \mathrm{a}$ \\
$1.500 \mathrm{~kg}^{-1} \mathrm{ha}^{-1}$ & $61,24 \mathrm{a}$ \\
$2.000 \mathrm{~kg} \cdot \mathrm{ha}^{-1}$ & \\
\hline Varietas & $69,15 \mathrm{~b}$ \\
\hline GMP 3 & $59,25 \mathrm{a}$ \\
GMP 19 & $60,36 \mathrm{a}$ \\
SS 57 &
\end{tabular}

$\overline{\text { Keterangan: Rerata pada kolom yang sama diikuti oleh huruf yang sama tidak berbeda nyata pada }}$ uji BNT taraf 5\%

Tabel 3 memperlihatkan bahwa varietas GMP 3 memiliki rerata bobot tebu 69,15 kg.kairan ${ }^{-1}$ dan berbeda nyata dengan varietas GMP 19 dan SS 57. Karakteristik varietas GMP 3 memiliki panjang ruas 13-15 cm sedangkan varietas GMP 19 dan SS 57 memiliki panjang ruas di kisaran kurang dari $13 \mathrm{~cm}$, sehingga semakin panjang ruas tebu maka akan semakin panjang batang tebu yang dihasilkan, sehingga dapat meningkatkan bobot tebu. Oleh karena itu, penggunaan varietas ini sangat dianjurkan untuk kegiatan budidaya karena dapat meningkatkan produktivitas.

\section{Jumlah Tebu per Kairan}

Berdasarkan hasil analisis sidik ragam menunjukkan bahwa pada perlakuan pemberian dosis pupuk organik padat dan penggunaan varietas berpengaruh nyata terhadap penambahan jumlah tebu per kairan, akan tetapi tidak terjadi interaksi pada penambahan jumlah tebu tersebut. Rerata pengaruh dosis pupuk organik padat dan varietas pada jumlah tebu per kairan dapat dilihat pada Tabel 4.

Tabel 4 menunjukkan bahwa hasil perlakuan pemberian dosis pupuk $1.000 \mathrm{~kg} \cdot \mathrm{ha}^{-1}$ memberikan jumlah batang tebu rata-rata 34,55 berbeda nyata dengan semua perlakuan. Hal ini diduga karena unsur hara yang dibutuhkan tanaman sudah terpenuhi secara optimal. Unsur hara yang diberikan secara berlebihan kapada tanaman tidak akan memberikan dampak yang positif, akan tetapi dapat menghambat pertumbuhan tanaman tersebut (Sunaryo, 2006).

Rerata jumlah tebu varietas GMP 3 yaitu 35,00 batang.kairan ${ }^{-1}$ lebih tinggi dibandingkan penggunaan kedua varietas yang lain. Hal ini diduga varietas ini memiliki sistem pertunasan yang lebih unggul di bandingkan varietas yang lain. Pertunasan sangat penting dalam hal menghasilkan banyaknya anakan tebu yang akan di panen nantinya. Sesuai dengan pernyataan Khuluq \& 
Hamidah (2014) bahwa perbanyakan anakan merupakan dasar terbentuknya total populasi dan jumlah batang terpanen.

Tabel 4. Rerata pengaruh dosis pupuk organik padat dan varietas pada jumlah tebu per kairan

\begin{tabular}{|c|c|}
\hline Perlakuan & Rerata jumlah tebu per kairan (batang.kairan ${ }^{-1}$ ) \\
\hline \multicolumn{2}{|c|}{ Dosis pupuk organik padat } \\
\hline Kontrol & $32,44 \mathrm{a}$ \\
\hline $1.000 \mathrm{~kg} \cdot \mathrm{ha}^{-1}$ & $34,55 \mathrm{~b}$ \\
\hline $1.500 \mathrm{~kg} \cdot \mathrm{ha}^{-1}$ & 33,11 a \\
\hline $2.000 \mathrm{~kg} \cdot \mathrm{ha}^{-1}$ & $29,22 \mathrm{a}$ \\
\hline \multicolumn{2}{|l|}{ Varietas } \\
\hline GMP 3 & $35,00 \mathrm{~b}$ \\
\hline GMP 19 & $30,41 \mathrm{a}$ \\
\hline SS 57 & 31,48 a \\
\hline
\end{tabular}

Keterangan: Rerata pada kolom yang sama diikuti oleh huruf yang sama tidak berbeda nyata pada uji BNT taraf 5\%

\section{Jumlah Ruas}

Berdasarkan hasil analisis sidik ragam menunjukkan bahwa pada perlakuan pemberian dosis pupuk organik padat dan penggunaan varietas berpengaruh nyata terhadap penambahan jumlah ruas tebu per batang, akan tetapi tidak terjadi interaksi pada penambahan jumlah tebu tersebut (Tabel 5).

Tabel 5. Rerata pengaruh dosis pupuk organik padat dan varietas pada jumlah ruas tebu

\begin{tabular}{ll}
\hline Perlakuan & Rerata ruas tebu (ruas.batang $^{-1}$ ) \\
\hline Dosis pupuk organik padat & $34,88 \mathrm{a}$ \\
\hline Kontrol & $38,55 \mathrm{~b}$ \\
$1.000 \mathrm{~kg} \cdot \mathrm{ha}^{-1}$ & $35,88 \mathrm{a}$ \\
$1.500 \mathrm{~kg}^{-1} \mathrm{ha}^{-1}$ & $35,77 \mathrm{a}$ \\
$2.000 \mathrm{~kg}^{-\mathrm{ha}^{-1}}$ & \\
\hline Varietas & $39,83 \mathrm{~b}$ \\
GMP 3 & $33.75 \mathrm{a}$ \\
GMP 19 & $35,25 \mathrm{a}$ \\
SS 57 & \\
\hline
\end{tabular}

Keterangan: Rerata pada kolom yang sama diikuti oleh huruf yang sama tidak berbeda nyata pada uji BNT taraf $5 \%$

118 Jurnal AIP Volume 5 No. 2 | Oktober 2017: 113-122 
Tabel 5 menunjukkan bahwa perlakuan pemberian dosis pupuk organik padat tidak berpengaruh nyata pada penambahan jumlah ruas tebu per batang. Hal ini diduga karena setiap tanaman memiliki kapasitas penyerapan unsur hara yang berbeda-beda. Menurut Rahmah et al. (2014) tanaman memiliki kemampuan dan batas tertentu yang berbeda-beda dalam hal penyerapan unsur hara.

Rerata ruas tebu GMP 19 adalah 33,75 buah perbatang, namun perlakuan ini dianggap tidak berbeda nyata pada varietas SS 57 berdasarkan hasil uji BNT 5\%, sedangkan untuk rerata jumlah ruas tebu per batang terbanyak di peroleh oleh varietas GMP 3 yaitu sebanyak 39,83 buah perbatang. Hal ini diduga karena setiap tanaman memiliki karakteristik fisiologis yang berbeda beda.

\section{Kandungan Sukrosa Tebu}

Hasil analisis sidik ragam menunjukkan bahwa pada perlakuan pemberian dosis pupuk organik padat tidak berpengaruh nyata sedangkan penggunaan varietas berpengaruh nyata terhadap kandungan sukrosa tebu dan tidak terjadi interaksi diantara keduanya (Tabel 6).

Berdasarkan nilai rata-rata dari perlakuan pemberian dosis pupuk organik padat 1.000 kg.ha ${ }^{-1}$ menunjukkan nilai tertinggi dibandingkan perlakuan lainnya, namun perlakuan ini dianggap tidak berbeda nyata dengan perlakuan lainnya berdasarkan uji BNT 5\%. Pada Tabel 6 menunjukkan bahwa varietas GMP 3 berpengaruh nyata terhadap dua varietas yang lainnya . Hal ini diduga varietas GMP 3 memiliki karakter genetik tanaman yang lebih baik yang ditunjukkan dari kemampuan adaptasi terhadap lingkungan. Produktivitas tebu juga bergantung pada varietas yang berkaitan dengan karakter genetik tanaman tersebut (Panwhar et al., 2003).

Tabel 6. Rerata pengaruh dosis pupuk organik padat dan varietas pada kandungan sukrosa tebu

\begin{tabular}{ll}
\hline Perlakuan & Rerata kandungan sukrosa tebu (\%) \\
\hline Dosis pupuk organik padat & $7,06 \mathrm{a}$ \\
\hline Kontrol & $7,38 \mathrm{a}$ \\
$1.000 \mathrm{~kg}^{\circ} \mathrm{ha}^{-1}$ & $6,80 \mathrm{a}$ \\
$1.500 \mathrm{~kg} \cdot \mathrm{ha}^{-1}$ & $6,53 \mathrm{a}$ \\
$2.000 \mathrm{~kg}^{-1} \mathrm{ha}^{-1}$ & \\
\hline Varietas & $7,91 \mathrm{~b}$ \\
\hline GMP 3 & $6,97 \mathrm{a}$ \\
GMP 19 & $6,09 \mathrm{a}$ \\
SS 57 &
\end{tabular}

Keterangan: Rerata pada kolom yang sama diikuti oleh huruf yang sama tidak berbeda nyata pada uji BNT taraf 5\% 
Berdasarkan Gambar 1, kandungan sukrosa tertinggi di dapatkan dari perlakuan pemberian dosis pupuk 1000 kg.ha ${ }^{-1}$ pada varietas GMP 3 sebesar 8,4 \%. Kandungan sukrosa terendah di tunjukkan pada kombinasi perlakuan pemberian dosis pupuk 2000 kg.ha-1 dan penggunaaan varietas SS 57 sebesar 5,52\%.

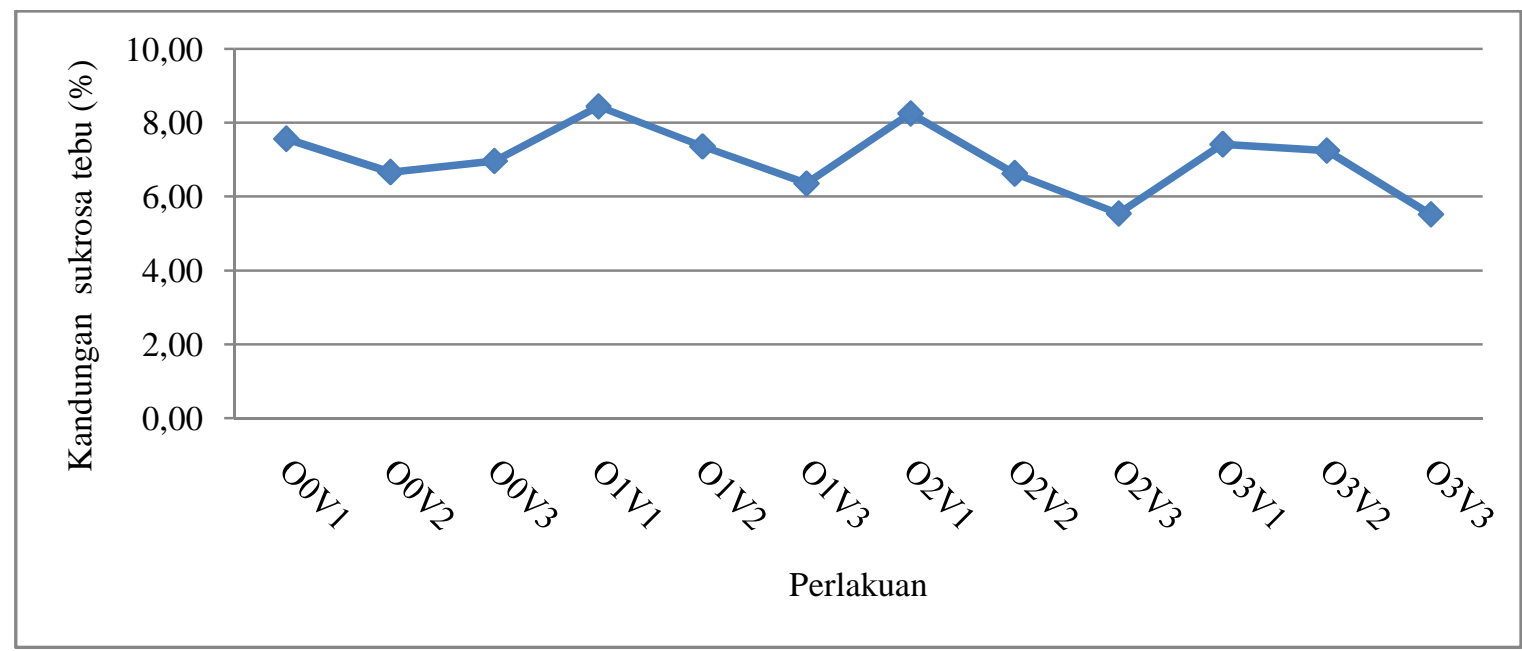

Gambar 1. Grafik kandungan sukrosa tebu perlakuan $\mathrm{O}$ x V pada umur $12 \mathrm{BST}$; $\mathrm{O}_{0}$ : kontrol (tanpa pupuk); $\mathrm{O}_{1}$ : dosis pupuk organik padat $1.000 \mathrm{~kg} \cdot \mathrm{ha}^{-1} ; \mathrm{O}_{2}$ : dosis pupuk organik padat $1.500 \mathrm{~kg} \cdot \mathrm{ha}^{-1} ; \mathrm{O}_{3}$ : dosis pupuk organik padat $2.000 \mathrm{~kg} \cdot \mathrm{ha}^{-1} ; \mathrm{V}_{1}$ : varietas GMP 3; $\mathrm{V}_{2}$ : varietas GMP 19; $\mathrm{V}_{3}$ : varietas $\mathrm{SS} 57$

Hal ini diduga karena adanya pertumbuhan tunas yang terlambat sehingga menyebabkan kandungan glukosa pada batang tebu digunakan untuk proses pemasakan digunakan untuk pertumbuhan tunas. Menurut Khuluq \& Hamidah (2014) menurunnya rendemen tebu disebabkan oleh terlambatnya pertumbuhan tunas.

\section{Produksi Tebu per Hektare}

Berdasarkan hasil analisis sidik ragam menunjukkan bahwa pada perlakuan pemberian dosis pupuk organik padat tidak berpengaruh nyata sedangkan penggunaan varietas berpengaruh nyata terhadap produktivitas tebu dan tidak terjadi interaksi diantara keduanya. Rerata pengaruh dapat dilihat pada Tabel 7.

Tabel 7 menunjukkan bahwa varietas GMP 3 memiliki rerata produktivitas tertinggi yaitu 107,40 ton.ha ${ }^{-1}$ dibandingkan varietas lainnya. Hal ini diduga karena varietas ini merupakan salah satu varietas unggul yang dapat menghasilkan jumlah anakan lebih banyak di bandingkan varietas lain yang digunakan untuk penelitian ini, sehingga dapat meningkatkan produktivitas. Pernyataan ini didukung dengan hasil penelitian Natarajan (2011) yang menyatakan bahwa faktor utama untuk memperoleh produktivitas yang tinggi sangat dipengaruhi oleh jumlah anakan tebu yang terbentuk. 
Tabel 7. Rerata pengaruh dosis pupuk organik padat dan varietas pada produktivitas tebu

\begin{tabular}{lc}
\hline Perlakuan & Rerata produktivitas tebu (ton.ha $\left.{ }^{-1}\right)$ \\
\hline Dosis pupuk organik padat & $100,47 \mathrm{a}$ \\
\hline Kontrol & $102,85 \mathrm{a}$ \\
$1.000 \mathrm{~kg} \cdot \mathrm{ha}^{-1}$ & $96,20 \mathrm{a}$ \\
$1.500 \mathrm{~kg} \cdot \mathrm{ha}^{-1}$ & $95,50 \mathrm{a}$ \\
$2.000 \mathrm{~kg} \cdot \mathrm{ha}^{-1}$ & \\
\hline Varietas & $107,40 \mathrm{~b}$ \\
\hline GMP 3 & $98,57 \mathrm{a}$ \\
GMP 19 & $93,20 \mathrm{a}$ \\
SS 57 &
\end{tabular}

$\overline{\text { Keterangan: Rerata pada kolom yang sama diikuti oleh huruf yang sama tidak berbeda nyata pada }}$ uji BNT taraf $5 \%$

\section{KESIMPULAN}

Berdasarkan hasil penelitian dapat disimpulkan dosis pupuk optimal adalah $1.000 \mathrm{~kg} \cdot \mathrm{ha}^{-1}$ yang berpengaruh pada jumlah tebu per kairan dan jumlah ruas tebu. Varietas terbaik yang dapat digunakan adalah varietas GMP 3 dan terdapat interaksi antara penggunaan dosis pupuk 1.000 kg.ha ${ }^{-1}$ dan varietas GMP 3 pada penambahan panjang tebu.

\section{DAFTAR PUSTAKA}

Craswell, E. T. \& Lefroy, R. D. B. (2001). The role and function of organic matter in tropical soils. Nutriens Cycling in Agroecosystems, 61, 7-18.

Direktorat Jenderal Perkebunan. (2014). Statistik perkebunan Indonesia 2013-2015. Jakarta: Direktorat Jenderal Perkebuunan.

Khairullah, P. S., E., Firmansyah, \& Harto, D. (2010). Pupuk Ghaly Organik. CV Rolies Lampung (Tidak dipublikasikan).

Khuluq, A. D. \& Hamida, R. (2014). Peningkatan produktivitas dan rendemen tebu melalui rekayasa fisiologis pertunasan. Perspektif, 13(1), 13-24.

Natarajan, U. S. (2011). Tillering in SSI-emergence, factors affecting, constraints and solutions. In First National Seminar on Sugarcane Sustainable Initiative (pp. 21-23).

Novizan. (2005). Petunjuk Pemupukan yang Efektif. Jakarta: Agromedia Pustaka.

Panhwar, R. N., Keerio, H. K., Khan, M. A., Aslam Rajpute, M., Sarwar Unar, G., Ishaq Mastoi, M., ... \& Rakhio Keerio, A. (2003). Relationship between yield and yield contributing traits in sugarcane (Saccharum officinarum L.). Journal of Applied Sciences, 3, 97-99. 
Prayogo, S. A., Minwal, M., \& Amir, N. (2016). Pengaruh jenis pupuk organik dan sistem tanam terhadap pertumbuhan bibit tanaman tebu (Saccharum officinarum L.). Klorofil: Jurnal Penelitian Ilmu-Ilmu Pertanian, 11(1), 51-55.

Putra, E., Sudirman, A., \& Indrawati, W. (2016). Pengaruh pupuk organik pada pertumbuhan vegetatif tanaman tebu (Saccharum officinarum L.) Varietas GMP 2 dan GMP 3. Jurnal Agro Industri Perkebunan, 4(2), 60-68.

Rahardjo, M., \& Pribadi, E. R. (2010). Pengaruh pupuk Urea, SP36, dan KCl terhadap pertumbuhan dan produksi temulawak (Curcuma xanthorhiza Roxb.). Jurnal Penelitian Tanaman Industri, 16(3), 98-105.

Rahmah, A., Izzati, M., \& Parman, S. (2014). Pengaruh pupuk organik cair berbahan dasar limbah sawi putih (Brassica chinensis L.) terhadap pertumbuhan tanaman jagung manis. Buletin Anatomi dan Fisiologi dh Sellula, 22(1), 65-71.

Sukmawan, Y. (2016). Peranan pupuk organik dan NPK majemuk terhadap pertumbuhan kelapa sawit TBM 1 di lahan marginal. Jurnal Agronomi Indonesia (Indonesian Journal of Agronomy), 43(3), 242-249.

Sunaryo, P. (2016). Pengaruh pupuk nitogen pertumbuhan dan hasil beberapa kultivar tebu pada tanah regosol coklat. Agrijati Jurnal Ilmiah Ilmu-ilmu Pertanian, 2(1), 55-62. 